\title{
DE ALUNO A PROFESSOR: PERCEPÇÕES SOBRE AULAS DE LITERATURA
}

\author{
FROM STUDENT TO TEACHER: PERCEPTIONS ABOUT \\ LITERATURE CLASSES
}

\section{DE ESTUDIANTE A PROFESOR: PERCEPCIONES SOBRE LAS CLASES DE LITERATURA}

Andressa Jove Godoy ${ }^{1}$
https://orcid.org/0000-0001-8437-8374

Fernando Stanzione Galizia ${ }^{2}$

https://orcid.org/0000-0002-9597-0733

${ }^{1}$ Universidade de Aveiro, Aveiro - Portugal. E-mail: andressa.godoy@ ua.pt.
${ }^{2}$ Universidade $\quad$ Federal
fernandogalizia@ de $\quad$ São

\section{Resumo}

Este artigo tem como objetivo apresentar, analisar e relacionar os modelos que nortearam as aulas de Literatura de educação básica que um licenciando concluinte do curso de Letras vivenciou como aluno, assim como os modelos que ele adota ao lecionar as aulas de Literatura, na sua prática profissional, como professor de Línguas na educação básica. Para isso foi conduzida uma entrevista na qual o participante pôde descrever as aulas de Literatura de que participou como aluno e que lecionou como professor e analisá-las sob a perspectiva do que foi chamado de definidores e demonstradores de modelo de aula: dinâmica de aula, conteúdo, material didático e avaliação. A partir da análise de suas respostas, constatou-se que as aulas de Literatura que frequentou como aluno da educação básica foram norteadas pelo modelo historiográfico, concluindo-se também que, apesar de mostrar-se insatisfeito com esse modelo, o participante, na sua atuação como professor, tende a reproduzir práticas que o caracterizam.

Palavras-chave: Formação de Professores. Modelos de Aula de Literatura. Didática da Literatura.

\section{Abstract}

This article aims to present, analyze, and relate the models that guided the basic education literature classes which a literature and language undergraduate experienced as student; and the models that he adopts to teach literature in his professional practices as language teacher on basic education. For that purpose, it was conducted an interview, in which the participant 
could describe the literature classes, both that he attended as student and teach as a teacher and analyze them from the perspective of what was called class model definers and demonstrators: class dynamics, content, didactic material and evaluation. Based on his answers, it was concluded that the literature classes which he attended as basic education student was guided by the historiographic model. It was also concluded that, although the participant had expressed dissatisfaction about that model, as a teacher, he tends to reproduce practices that characterize it.

Keywords: Teacher Training. Literature Class Models. Didactics of Literature.

\section{Resumen}

Este artículo tiene como objetivo presentar, analizar y relacionar los modelos que guiaron las clases de Literatura de educación básica a las que un estudiante del curso de Letras ha asistido como alumno, así como los modelos que adopta para enseñar Literatura en sus prácticas profesionales como profesor de lengua en educación básica. Para ello, se realizó una entrevista en la cual el participante pudo describir las clases de Literatura de las cuales participó como alumno y las que enseñó como docente y analizarlas desde la perspectiva de lo que se denominó definidores y demostradores de modelo de clase: dinámica de clase, contenido, material didáctico y evaluación. A partir de sus respuestas se constató que las clases de Literatura a las que asistió como alumno de educación básica se guiaron por el modelo historiográfico, concluyéndose también que, aunque el participante ha expresado su descontento sobre ese modelo, como docent, tiende a reproducir prácticas que lo caracterizan.

Palabras clave: Formación de Profesores. Modelos de Clases de Literatura. Didáctica de la Literatura.

\section{Introdução}

A partir de teorias elaboradas por estudiosos da Literatura e de seu ensino, como Abreu (2006), Candido (1995), Colomer (2017), Cosson (2018), Lajolo (1983) e Zilberman (2009), é possível defender que os processos de ensino e de aprendizagem de Literatura podem ter como função principal o desenvolvimento da consciência crítica e do hábito de leitura dos leitores em formação.

Para isso, seria necessário, segundo Paulino e Cosson (2009), que as habilidades para a leitura literária fossem formadas em um "processo de apropriação da literatura enquanto construção de sentidos" (Id. ibid., p. 67), que se daria por meio da interação verbal intensa demandada pela Literatura, do "(re)conhecimento do outro e [d]o movimento de desconstrução/construção do mundo" pela experimentação literária (Id. ibid., p. 69-70).

Em contrapartida, os autores indicam que o modelo de aula de literatura majoritariamente vigente no Brasil é constituído pelo que eles chamam de "biografismo" e "historicismo monumentalista", que dão tons de "elitismo cultural de fachada" ao ensino 
escolar da Literatura, "em que o conhecimento é aprendido sem integrar-se às vidas dos alunos enquanto sujeitos" (PAULINO; COSSON, 2009, p. 70-71).

Tendo em vista a discrepância que pode ser identificada entre as expectativas teóricas para a formação de leitores literários e o que é constatado em salas de aula de educação básica brasileira, considera-se fundamental analisar criticamente a formação de formadores de leitores de Literatura, ou seja, a formação de professores de Línguas.

Por isso, realizou-se uma pesquisa (GODOY, 2019), que teve como objetivo principal investigar os impactos dos modelos de ensino de literatura durante o percurso formativo na universidade e na educação básica nas concepções de ensino de Literatura de licenciandos em Letras. A pesquisa foi desenvolvida como estudo multicasos com dois alunos concluintes do curso de licenciatura em Letras de uma universidade federal ${ }^{1}$. Desses estudantes, um já atuava profissionalmente como professor de literatura e o outro nunca o havia feito como professor fora do contexto formativo de estágios. Os participantes contribuíram com o processo de construção dos dados analisados ao participarem de entrevistas semiestruturadas, nas quais foram convidados a descrever e a refletir sobre as suas aulas de Literatura na educação básica, no ensino superior e na prática profissional ${ }^{2}$.

Neste artigo, são abordadas as descrições e reflexões do sujeito que já atuava profissionalmente como professor de Literatura do ensino médio, José Carlos ${ }^{3}$, com os objetivos de identificar, analisar e relacionar os modelos que nortearam as aulas que compuseram sua formação literária como aluno de educação básica e aqueles que ele adota ao lecionar as aulas de Literatura na sua prática profissional como professor de educação básica. A apreciação crítica dos discursos de José Carlos sobre suas aulas de Literatura na educação básica, ora como aluno, ora como professor, justifica-se pela importância da experiência dos professores como alunos na constituição da identidade docente e da influência das atuações de seus próprios mestres na formação de suas práticas profissionais (GONÇALVES PINTO, 2004; TARDIF, 2002).

Para tanto, serão expostos, na próxima seção, os modelos de aula de Literatura, o enquadramento teórico adotado para caracterizar os dois modelos de aula de Literatura

\footnotetext{
${ }^{1}$ Optou-se pela não identificação da instituição onde a pesquisa foi realizada como forma de preservar a identidade dos participantes.

${ }^{2}$ Esta pesquisa cumpriu as normas éticas em pesquisa e foi aprovada pelo Comitê de Ética da instituição de ensino na qual foi realizada (CAAE 01000118.0.0000.5504).

${ }^{3}$ Pseudônimo escolhido pelo participante com a finalidade de preservar sua identidade.
} 
identificados e analisados ao longo da pesquisa, o modelo historiográfico e o modelo por letramento literário. Seguidamente, serão expostas as análises sobre as considerações de José Carlos sobre as aulas de Literatura que frequentou como aluno e que lecionou como professor, em seções que observam isoladamente cada um dos definidores e demonstradores do modelo de aula de literatura: dinâmica de aula; conteúdo abordado; material utilizado e avaliação. Por fim, em atenção ao anteriormente exposto, serão tecidas as considerações desenvolvidas por meio da reflexão proposta.

\section{Os modelos de aula de literatura}

A divergência já aludida entre o processo de formação literária proposto pelos teóricos mencionados anteriormente e o modelo amplamente adotado na maioria das escolas do Brasil, também já demonstrada neste texto, se dá fundamentalmente pela diferença de enfoque. Isso porque, segundo Leahy-Dios (2004), os processos de ensino e de aprendizagem da Literatura e da Leitura Literária como disciplinas curriculares são sustentados "por um triângulo interdisciplinar composto da combinação assimétrica de estudos da língua, estudos culturais e estudos sociais" (2004, p. XX ${ }^{4}$ ). A autora aponta para a variabilidade do enfoque dado a cada um dos vértices desse triângulo e, consequentemente, da abordagem escolar da literatura, a depender da ideologia dominante. Ela ainda sustenta que, no Brasil, esse triângulo "tem seu ápice oscilante entre a ênfase acrítica ao saber historiográfico e ao treinamento linguístico”, concluindo, portanto, que a "literatura como expressão artística da cultura do povo e da nação brasileira é o aspecto ignorado do triângulo" (Id. ibid., p. 183).

A educação literária com foco na língua e na história da arte, utilizada massivamente na educação básica brasileira (LEAHY-DIOS, 2004; PAULINO, COSSON, 2009), dá-se a partir da realização de aulas de literatura que seguem o modelo historiográfico. Esse modelo é caracterizado por: valorizar o aluno repetidor, "cuja competência mais valorizada é dizer aquilo que o livro didático ou o professor já disse" (PAULINO, COSSON, 2009, p. 71); sobrepor a obrigatoriedade escolar à fruição literária (Id. ibid.); e pautar tópicos de ensino e de aprendizagem que respondem a interesses utilitários, objetivos e pseudocientíficos, pouco ligados à vida real e a fatos atuais que sejam facilmente mensuráveis em provas e testes "através

\footnotetext{
${ }^{4}$ Algumas citações da obra de Leahy-Dios (2004) foram retiradas de elementos peritextuais, de forma que sua paginação é marcada, assim como no livro, em algarismos romanos.
} 
de períodos, datas, nomes e características", a despeito da leitura real dos textos literários (LEAHY-DIOS, 2004, p. 37).

Em outro sentido, a escola que se julga necessária diante do atual momento sóciohistórico brasileiro em que estamos deve funcionar como "elemento de transformação" e em prol da "prática de liberdade" (ZILBERMAN, 2009, p. 26). Dessa forma, ela não pode ser um local apenas de práticas de "transmissão rígida do saber e da cultura" ou de "despejar de relatos ou fatos sobre o educando" (LEAHY-DIOS, 2004, p. 168). Tendo isso em vista, é necessário que o modo de ensinar Literatura a partir do modelo historiográfico seja revisto, de forma que o poder entre docentes e discentes seja compartilhado "democraticamente na busca de interpretações significativas do artefato literário, oferecendo leituras variadas e de real significado multicultural” (Id. ibid., p. 169).

Uma proposta de nova abordagem, que contempla esses objetivos do ensino da Literatura, é o letramento literário, que, segundo Paulino e Cosson (2009), pressupõe que a aprendizagem de Literatura seja vista como um processo de construção de sentidos e "um estado permanente de transformação, uma ação continuada" (p. 67-8), e não como uma habilidade adquirida ou conhecimento mensurável, com início e fim na escola, sem abertura para a subjetividade. Para isso, propõe-se um modelo em que a educação literária contemple “objetivos, métodos e formas de avaliação coerentes com o processo de construção de conhecimento, utilizando a leitura, análise e interpretação do literário como meio de educar cidadãos" (LEAHY-DIOS, 2004, p. 7), de modo a "oferecer meios de resistência às tendências desenraizadoras consequentes à domesticação acrítica, dando voz àqueles que foram silenciados na criação e desenvolvimento das culturas sociais" (Id. ibid., p. 176).

Com base nos conceitos e descrições dos modelos de aula de literatura historiográfico e por letramento literário, foi possível identificar que eles se diferenciam principalmente em quatro aspectos que foram chamados de definidores e demonstradores de modelo de aula de Literatura (Quadro 1). 
Quadro 1 - Definidores e Demonstradores.

\begin{tabular}{|c|l|}
\hline Dinâmica de aula & $\begin{array}{l}\text { Formas de condução das aulas e relacionamento estabelecido entre seus } \\
\text { atores }\end{array}$ \\
\hline Conteúdo abordado & Tópicos de ensino e de aprendizagem \\
\hline Material utilizado & Tipos de materiais didáticos adotados e papel que eles exercem em aula \\
\hline Avaliação & Tipos de instrumentos avaliativos que são empregados e com qual finalidade \\
\hline
\end{tabular}

Fonte: Produção própria.

Esses aspectos foram observados e analisados nas descrições das aulas de Literatura de José Carlos, tanto quando aluno da educação básica, quanto quando professor, em sua prática profissional. As consequentes reflexões são expostas, respectivamente, nas seções subsequentes do texto.

\title{
3 Dinâmica de aula
}

Ao retratar as aulas de Literatura que frequentou ao longo de sua vivência como aluno da educação básica, José Carlos estabelece a relação dúbia entre as chamadas aulas de leitura, do ensino fundamental, e as aulas chamadas de Literatura, do ensino médio:

\begin{abstract}
Me lembro que, quando entrei no ensino fundamental, havia uma disciplina chamada aula de leitura. Então até a quinta ou sexta séries, se não me engano, isso [ter contato e ler obras de literatura para a escola] aconteceu. Depois isso não aconteceu mais: vieram os jornais ${ }^{5}$ e começou toda uma mudança. [...] o próprio contato das aulas de português com a biblioteca já não acontecia. O que acontecia no fundamental, no médio não acontecia mais. Mas essas aulas de leitura eu aproveitei bastante e foi através dela que eu conheci a biblioteca.
\end{abstract}

As diferenças entre práticas adotadas para a composição das aulas que têm como objeto de ensino e aprendizagem a Literatura nos ensinos fundamental e médio foram alvos dos

${ }^{5} \mathrm{O}$ referenciado Jornal diz respeito ao Jornal do Aluno, componente do material didático alinhado ao currículo da Secretaria da Educação do Estado de São Paulo no ano de 2008, que foi formulado e distribuído também por essa secretaria. Recebeu esse nome porque, mesmo cumprindo a função e portando conteúdo que o aproximasse de um manual ou apostila escolar, foi desenvolvido no formato estético de um jornal (Fonte: SEE/SP. Secretaria de Estado da Educação de São Paulo. Proposta Curricular do Estado de São Paulo: Educação Física. São Paulo: SEE. 2008). 
estudos de Cosson (2018). O autor aponta que as distinções na adoção da literatura em diferentes fases da escolarização podem ocorrer em decorrência da não unidade daquilo que se compreende por literatura, assim como da função de sua abordagem nas escolas.

De acordo com o autor (COSSON, 2018), no ensino fundamental, período escolar em que a literatura exerce a função de "sustentar a formação do leitor" (p. 20), ela "tem um sentido tão extenso, que engloba qualquer texto escrito que apresente parentesco com ficção ou poesia" (p. 21) e é, de forma crescente, substituída em sala de aula por textos não-ficcionais. Já no ensino médio, a literatura é abordada, em tese, para que o leitor em formação possa ser integrado à cultura brasileira (COSSON, 2018, p. 20), valendo-se, para isso, da abordagem da

\begin{abstract}
história da literatura brasileira, usualmente na sua forma mais indigente, quase como apenas uma cronologia literária, em uma sucessão dicotômica entre estilos de época, cânone e dados biográficos dos autores, acompanhada de rasgos teóricos sobre gêneros, formas fixas e alguma coisa de retórica (COSSON, 2018, p. 21).
\end{abstract}

Cosson (2018, p. 21) ainda denuncia que, quando os textos literários são efetivamente lidos nas aulas de Literatura do ensino médio, "são fragmentos e servem prioritariamente para comprovar as características dos períodos literários antes nomeadas”, com raras “oportunidades de leitura de um texto integral" (p. 22).

As formas com que a literatura se apresenta nos diferentes níveis escolares, descritas por José Carlos, em sua entrevista, e por Cosson, em sua obra (2018), apesar de distintas, não são dicotomizadas quando analisadas da perspectiva dos modelos de aula de Literatura observados. Isso porque ambas adotam o texto literário como ferramenta para o desenvolvimento de habilidades e competências para a leitura enquanto código, no ensino fundamental, e de conhecimentos acerca da literatura, no ensino médio, de modo que podem, ambas, ser orientadas pelo modelo historiográfico.

A vontade de abordar a Literatura de forma diferente em suas aulas como professor foi expressa por José Carlos durante a entrevista, que salientou a importância da presença e da manipulação do texto na abordagem da literatura:

Eu acho que nada substitui o contato com o próprio texto. [...] O professor tem que ler o texto, tem que entendê-lo, tem que brincar com ele e fazer com que ele vá para a sala de aula e que vá de uma forma dinâmica para o aluno poder entrar de fato no 
texto, então eu acho que eu mudaria isso [nas aulas que tive no ensino fundamental e médio].

No entanto, quando questionado sobre o funcionamento e as dinâmicas que adota nas aulas em que atua como professor, a leitura de textos literários per si não é abordada por José Carlos, que enumera atividades como a conversa e a visualização do material por ele preparado e exposto em slides, além da leitura de imagens relacionadas com o tópico literário estudado, de modo que as práticas identificadas e criticadas por Cosson (2018) no modelo de aula de Literatura historiográfico continuam sendo preponderantes nas aulas ministradas pelo entrevistado:

Eu monto a aula toda no slide, eu uso muito pouco a lousa. Prefiro eles numa roda, conversando comigo e vendo os slides, interagindo, do que resolvendo exercícios ou fazendo outras coisas... A minha aula foca bastante nos slides, eu os uso bastante. Ao invés de escrever, eu coloco imagens [...], eu uso imagens, eu uso quadros, eu uso outras fontes de visualização que não seja só uma explicação [...], fazemos uma análise do quadro... os slides me ajudam muito nesse sentido.

A partir da observação das dinâmicas de aula de Literatura relatadas por José Carlos em suas experiências como aluno e professor da educação básica, foi possível constatar que o texto literário continua não estando presente, mas, sim, outros elementos, como slides e quadros. Isso sugere a continuidade da adoção de práticas próprias ao modelo historiográfico, mesmo que o participante tenha expressado descontentamento em vivenciá-las como estudante e pretensões em não as reproduzir como professor.

Para além disso, a análise das descrições de José Carlos sobre suas idealizações e práticas permite verificar a importância da vivência como aluno na construção da identidade docente. Isso porque, conforme Gonçalves Pinto,

não é preciso que se esteja desempenhando a profissão docente para ter uma referência sobre o que envolve ser professor, ainda mais nesse caso, em que todos nós, em princípio, passamos por algum desses profissionais. Muitas dessas referencias, tenham sido elas boas ou nem tão boas assim, serão inspiradoras para a construção do nosso próprio caminho, demarcando o que se quer, o que não se quer e o que se pode ser como professor(a) (2004, p. 370-371). 
Essas constatações também puderam ser verificadas na análise dos relatos referentes ao definidor e demonstrador conteúdo abordado, exposto no tópico seguinte.

\title{
4 Conteúdo abordado
}

Ao refletir sobre a sua formação na educação básica, José Carlos sinalizou, por diversas vezes, a escassez de aulas de Literatura na escola onde estudou. De acordo com as percepções do licenciando, a falta de ensino de textos literários dava-se, principalmente, pela preferência de suas professoras por tópicos e conteúdo mais palpáveis:

\begin{abstract}
As aulas de literatura em si, eu não digo que aproveitei muito, porque o foco não era tanto na literatura na escola onde eu estudei. [...] Eu acho que o foco da escola pública naquele momento era outro. Era um foco muito mais gramatical. Lembro que eu fazia cópias e cópias de frases e tinha que analisá-las de todas as formas possíveis: sintaticamente, morfologicamente [...] elas [professoras] iam desistindo aos poucos e eu acredito que o foco era no que é mais palpável e por isso partia-se para a gramática. Interpretação de texto e a literatura eram um pouco escanteadas.
\end{abstract}

Segundo José Carlos, os poucos momentos dedicados à literatura ao longo de sua educação básica giraram em torno de tópicos que lhe eram circundantes, tendo em vista que o texto literário não figurava nas aulas e que a literatura e a interpretação não eram incentivadas:

O texto não chegava [aos alunos]. Às vezes chegavam características de uma escola literária e passava-se rasamente [pelo texto], mas livro lido em si, texto não chega. [...] O professor ler e fazer comentários ou sequer o professor ler e pedir que os alunos conversem? Não havia isso!

Essas considerações tecidas por José Carlos sobre as aulas da educação básica nas quais supostamente deveria ter desenvolvido competências que o habilitassem para ler e interpretar criticamente textos literários demonstram a posição "escanteada”, para usar suas palavras, desse tópico nas aulas de Línguas em detrimento de um conteúdo mais "palpável”, ou, segundo Leahy-Dios (2004), “objetivos facilmente mensuráveis”.

Esse tipo de conteúdo, na descrição das aulas de José Carlos como aluno, é mais ligado ao vértice linguístico do triângulo conceptualizado por Leahy-Dios (2004), mas também pode assumir contornos históricos e culturais, materializados em datas, dados biográficos, nomes de 
autores e características de escolas literárias, que parecem ser os tópicos de ensino e aprendizagem norteadores das aulas ministradas pelo entrevistado:

\begin{abstract}
No segundo bimestre, por exemplo, é Memórias de Um Sargento de Milícias [o livro que trabalho com meus alunos]. É um livro bacana, interessante, mas eles [seus alunos] ainda não aprenderam o Romantismo. Eu acho muito fora de contexto, eu não gosto de trabalhar, eu não consigo trabalhar isso sem eles saberem o Romantismo, então acabo levando outros textos.
\end{abstract}

Nessa fala, em que critica a organização curricular da disciplina de Literatura na escola em que atua como professor, José Carlos condena a incongruência da sugestão do estudo da obra de Manuel Antônio de Almeida, comumente descrita como um livro de transição entre o Romantismo e o Realismo, antes que os alunos dominem as concepções da escola literária romântica. Percebe-se então que, para o professor José Carlos, o estudo da Literatura pressupõe um conhecimento prévio do contexto e da escola artística referente, crença característica do modelo de aula historiográfico.

Para além disso, chama a atenção que o entrevistado, antes crítico da ausência da leitura do texto literário em suas aulas de Literatura, use o verbo "trabalhar" para se referir às atividades a serem realizadas com a obra estudada, e não o verbo "ler". Também se nota que, assim como visto nas descrições de suas aulas de Literatura da educação básica, a opção por um ou por outro conteúdo é feita com base na preferência e na aptidão do docente, seja ela a "mais palpável" (gramática), quando José Carlos atuava como aluno, ou o texto considerado mais contextualmente adequado, como professor.

Com a prerrogativa da ausência do livro ou qualquer outro suporte que contemple o texto literário na íntegra, passa-se à análise dos materiais didáticos utilizados nas aulas de literatura de José Carlos.

\title{
5 Material utilizado
}

Por conta da ausência de livros ou qualquer outro suporte que contemplasse o texto literário, José Carlos afirmou que o principal material didático de que dispunha, quando aluno, era o oferecido pela rede estadual de ensino, em formato apostilado. Chamado por José Carlos 
de "cadernos", o material fornecia, em literatura, segundo ele, fragmentos de textos tomados como exemplares da escola literária estudada:

A literatura era quase que absolutamente nada naqueles cadernos, o pouco que apareceu foram fragmentos. [...] Não havia contextualização daquele fragmento. [...] Apenas [a informação] que aquele fragmento era parte de um texto de um autor que pertencia àquela escola que o professor tinha acabado de dar as características...

Já na sua atuação como professor, José Carlos conta com seus slides, descritos anteriormente, e o material didático desenvolvido pela rede de ensino da qual o colégio faz parte:

\begin{abstract}
Nós temos a nossa apostila de exercícios, tem o livro de teoria deles, também tem outro caderno só de exercícios de vestibulares e um livro obrigatório de leitura todo o bimestre, que não sou eu que escolho [...] Então, os exercícios são divididos em módulos: módulo um, Trovadorismo; módulo dois, Humanismo; módulo três... e por aí vai. Na outra apostila, tem teoria, que é bem rasa [...]
\end{abstract}

Pela análise dos discursos de José Carlos sobre o material didático utilizados nas suas aulas de Literatura na educação básica, como aluno e como professor, constata-se que não somente a dinâmica de aula e o conteúdo abordado são persistentemente definidos por características do modelo historiográfico, mas também o material didático disponibilizado.

A percepção de que se continua a produzir e a adotar materiais didáticos definidos por características do modelo de aula historiográfico tem consequências particularmente dramáticas nos casos de sistemas apostilados, como os utilizados por José Carlos como aluno e como professor. Isso porque, na maioria das vezes, esses materiais tendem a ser definidos como a corporização do conteúdo e o centro do processo de ensino e aprendizagem, relegando ao professor apenas o papel de aplicador, e, ao aluno, o de receptor ${ }^{7}$ de conteúdo, já que, nesses

\footnotetext{
${ }^{6} \mathrm{Na}$ esteira do projeto que implementou o Jornal do Aluno, em 2008, na Rede Estadual de Ensino de São Paulo, desde 2009 vêm sendo distribuídos nas instituições integrantes o Caderno do Aluno e o Caderno do Professor, que, diferentemente do anterior, são produzidos em formato de apostila. No entanto, a despeito da diferença estética, os Cadernos... mantiveram a função do Jornal...: a unificação do currículo das escolas públicas estaduais de São Paulo. Segundo o site institucional, os alunos da rede matriculados nos anos finais do ensino fundamental e no ensino médio "contam com material exclusivo desenvolvido por especialistas da Educação. O Caderno do Aluno chega às salas de aula por meio do programa São Paulo Faz Escola duas vezes ao ano. Fonte: Caderno do Aluno. Disponível em: https://www.educacao.sp.gov.br/caderno-aluno. Acesso em: jul. 2020.

${ }^{7}$ Segundo Mizukami (1986), a abordagem que prioriza a tecnologia educacional atribui ao professor o ofício de controlar e administrar o processo de aprendizagem e, aos alunos, o papel de receptor de informações e reflexões
} 
cenários, o material didático exerce o papel de centro catalisador do funcionamento de todas os demais demonstradores e definidores do modelo de aula de Literatura ${ }^{8}$.

Como já foram analisados a dinâmica de aula, o conteúdo abordado e o material utilizado, observam-se criticamente, na seção seguinte, os modos de avaliação aos quais José Carlos foi submetido como aluno, além dos que promoveu como professor de literatura.

\section{Avaliação}

As características das escolas literárias e seus respectivos autores e obras, aprendidos com a ajuda dos materiais descritos, em aulas que seguiam as dinâmicas já observadas, eram temas das questões que compunham as avaliações de literatura de José Carlos quando aluno. De acordo com seu relato exemplificativo, essas avaliações eram sempre escritas e tinham o objetivo de verificar as habilidades dos alunos de lembrar as informações com as quais tiveram contato nas aulas, demonstrando forte vínculo com os tipos de avaliação do modelo historiográfico:

\footnotetext{
Era basicamente escrito, nessa mesma forma: "Vamos lá! Tira uma folha do caderno, copia as dez questões da lousa, responde, entrega". A avaliação não passava disso. A perguntas, [...] no romantismo, por exemplo, são [sobre] as datas, o início disso, o fim daquilo, o começo de um autor, características, autores, qual a diferença entre Gonçalves Dias e Gonçalves de Magalhães, essas coisas... mas o texto em si, a obra em si, nada!
}

Ao tratar da avaliação em sua atuação profissional como professor de Literatura, seja por zelo e receio em abrir a "caixa preta" da sala de aula (SIROTA, 1994), seja por não deter o controle dos processos avaliativos na instituição em que trabalha, José Carlos pouco descreveu e ponderou sobre as estratégias avaliativas adotadas ${ }^{9}$. Mesmo que o participante tenha detalhado e refletido com menos intensidade sobre esse aspecto das aulas que leciona, considerou-se

\footnotetext{
é a comportamental. Em Godoy (2019), é mais amplamente discorrido sobre as relações entre as abordagens de ensino definidas por Mizukami e os modelos de aula de Literatura.

${ }^{8}$ Ainda nesses casos, defende-se que a formação, inicial e continuada, de professores de Literatura que contemple questões didáticas, pedagógicas e de letramento literário seria a melhor forma de combater um modelo insuficiente de formação de leitores, conforme é exposto nas Considerações, última seção deste texto.

${ }^{9}$ Entretanto, com base em colocações suas sobre o material didático disponibilizado pela escola, é possível depreender que é dada certa importância aos vestibulares como mecanismo avaliativo. Sobre a abordagem da literatura nesses exames discorrem Luft (2019); Suassuna e Silva (2019); Venção (2019); Dalvi, Schwartz e Tragino (2015); Fischer et al. (2012).
} 
importante que o definidor e demonstrador relacionado à avaliação constasse nesse estudo para que, dessa forma, fosse possível construir um quadro panorâmico dos modelos de aula de literatura por ele presenciado, tanto como aluno quanto como professor.

Com isso, é concluída a análise dos definidores e demonstradores de modelos de aula de Literatura vivenciados por José Carlos, o que possibilita que sejam elaboradas considerações sobre a relação entre as experiências do aluno e as práticas e concepções do professor. Essas considerações são apresentadas na seção seguinte.

\section{Considerações}

Como mencionado anteriormente, este trabalho apresenta um recorte dos dados e análises realizados a partir de uma pesquisa (Godoy, 2019) que teve como objetivo principal investigar os impactos dos modelos de ensino de Literatura durante o percurso formativo na universidade e na educação básica nas concepções de ensino de Literatura de licenciandos em Letras.

Dados os objetivos principais deste texto, apresentar, analisar e relacionar os modelos que nortearam as aulas de Literatura de educação básica que um licenciando concluinte do curso de Letras vivenciou como aluno, assim como os modelos que ele adota ao lecionar as aulas de Literatura na sua prática profissional, como professor de Línguas na educação básica, foram observadas, para a sua construção, as experiências de José Carlos, licenciando que já atuava como professor de Literatura profissional, como aluno e como professor da educação básica.

Ao longo deste texto, foram demonstradas e analisadas as percepções e reflexões que José Carlos expressou sobre as dinâmicas, os conteúdos, os materiais e as avalições que compunham as aulas de Literatura que vivenciou como aluno da educação básica e que compõem aquelas que ele leciona como professor.

A partir disso, foi possível constatar a preponderância do modelo historiográfico de aula de Literatura em sua experiência como estudante. Esse modelo, de acordo com o definido por Leahy-Dios (2004) e Paulino e Cosson (2009), preza pelo ensino e aprendizagem de conteúdos utilitários e facilmente memorizáveis, muito diferente do modelo por letramento literário, que se utiliza da leitura e da interpretação do texto como meio para o desenvolvimento de habilidades e competências para a leitura crítica. 
Mesmo que José Carlos reconheça a ausência do texto literário e a importância de "trabalhá-lo" nas aulas de Literatura, quando os relatos de suas atuações como professor são observados, é possível perceber que muitas das nuances próprias do modelo historiográfico são reproduzidas, o que reitera a influência das práticas pedagógicas de professores na formação de novos professores, conforme abordado por Gonçalves Pinto (2004) e Tardif (2002).

Dessa forma, verifica-se que José Carlos tende a replicar práticas de professores com os quais teve contato durante sua educação básica. Essa tendência à réplica de práticas de seus professores de Literatura da educação básica, mesmo tendo demonstrado não as aprovar como aluno, pode ser atribuída, entre outros motivos, a uma formação insuficiente em didática da Literatura. Essa hipótese é reforçada ao se terem em atenção as descrições das aulas de Literatura que José Carlos teve em sua licenciatura, expostas e analisadas em Godoy (2019), já que o licenciando aponta a ausência de disciplinas que lhe proporcionassem momentos de formação e reflexão sobre as formas de aprender e ensinar Literatura.

Esse movimento, se não revisto, possibilitará a consolidação, cada vez mais, de um ciclo vicioso que enfraquece o desenvolvimento de uma educação literária brasileira que esteja organizada mais equilibradamente entre seus três vértices (LEAHY-DIOS, 2004) e habilitada para formar leitores engajados e críticos.

Para isso, faz-se necessária a realização de reflexões em âmbito acadêmico e na formação inicial e continuada de professores sobre a didática da Literatura e o letramento literário. A partir disso, será possível desenvolver, junto aos professores de Línguas, embasamento para que analisem as práticas de seus antigos professores com criticidade, de modo a poderem definir autonomamente quais são as práticas e os conceitos adotados por eles mais adequados aos objetivos de ensino e ao modelo de aula de Literatura que desejam e em que acreditam.

Por fim, cabe ressaltar que, eventualmente, José Carlos citou, na pesquisa realizada, títulos e autores de literatura como forma de exemplificação e ilustração dos processos de ensino e de aprendizagem da Literatura. Porém, esses ou outros autores e textos literários não foram relacionados e analisados neste artigo em consideração à fundamentação teórica, o escopo e os objetivos desta pesquisa, que demandavam atenção às formas que os textos literários, fossem eles quais fossem, (não) eram abordados nas aulas de Línguas e de Literatura.

De toda forma, defendem-se a importância e a necessidade da análise das obras literárias escolhidas para serem lidas e abordadas em contexto escolar, já que elas também 
podem ser elementos caracterizadores de modelos de aula de Literatura, constituindo-se, portanto, como objeto de pesquisa promissor para futuros projetos que tenham o tema do ensino de Literatura como foco.

\section{Referências}

ABREU, M. Cultura letrada - Literatura e leitura. São Paulo: UNESP, 2006.

CANDIDO, A. O direito à Literatura. In: CANDIDO, A. Vários escritos. São Paulo: Duas Cidades, 1995.

COLOMER, T. Introdução à literatura infantil e juvenil atual. São Paulo: Global, 2017.

COSSON, R. Letramento literário: teoria e prática. 2. ed. São Paulo: Contexto, 2018.

DALVI, M. A.; SCHWARTZ, C. M.; TRAGINO, A. A literatura no vestibular: traços de seu histórico e olhares recentes. Via Atlântica, São Paulo, n. 28, p. 215-230, 2015.

FISCHER, L. A; LUFT, G.; FRIZON, M.; LEITE, G.; LUCENA, K.; VIANNA, C.;

WELLER, D. A Literatura no Exame Nacional do Ensino Médio (ENEM). Nonada: Letras em Revista, Porto Alegre, v. 1, n.18, p. 111-126, 2012.

GODOY, A. J. Modelos de aula de literatura e seus impactos na formação de licenciandos em letras. 2019. 99 f. Monografia (Licenciatura em Letras) - Universidade Federal de São Carlos, 2019.

GONÇALVES PINTO, M. G. C. S. M. A formação do(a) professor(a) de educação superior: identidades e práticas. In: ANAIS DO ENCONTRO NACIONAL DE DIDÁTICA E PRÁTICA DE ENSINO - ENDIPE, 12, 2004, Curitiba. Anais [...]. Curitiba: ENDIPE, 2004, CD-ROM.

LAJOLO, M. O que é literatura. 3. ed. São Paulo: Brasiliense, 1983.

LEAHY-DIOS, C. Educação literária como metáfora social: desvios e rumos. 2. ed. São Paulo: Martim Fontes, 2004. (Coleção Texto e Linguagem).

LUFT, G. F. C. A abordagem da Literatura no Exame Nacional do Ensino Médio (ENEM): uma análise das provas de 2017 e 2018. Muitas vozes, Ponta Grossa, n. 2, p. 132-145, 2019.

MIZUKAMI, M. G. N. Ensino: as abordagens do processo. São Paulo: Editora Pedagógica e Universitária, 1986. (Temas básicos de educação e ensino).

PAULINO, G.; COSSON, R. Letramento literário: para viver a literatura dentro e fora da escola. In: ZILBERMAN, R.; RÖSING T. M. K (org.). Escola e leitura: velha crise, novas alternativas. São Paulo: Global, 2009. (Coleção Leitura e Formação). p. 61-79.

SIROTA, R. A escola primária no cotidiano. Porto Alegre: Artes Médicas, 1994. 
GODOY, A. J.; GALIZIA, F. S.

SUASSUNA, L.; SILVA, T. L. A literatura em provas e exames: vestibular da UFPE e Enem. Estud. Aval. Educ., São Paulo, v. 30, n. 74, p. 362-391, 2019.

TARDIF, M. Saberes Docentes e Formação Profissional. Petrópolis: Vozes, 2002.

VENÇÃO, P. V. C. A literatura no enem (2013-2017): reflexões sobre ensino e formação de leitores. 2019. 171 f. Dissertação (Mestrado em Letras) - Universidade Federal do Piauí. 2019.

ZILBERMAN, R. A escola e a leitura de literatura. In: ZILBERMAN, R.; RÖSING T. M. K (org.). Escola e leitura: velha crise, novas alternativas. São Paulo: Global, 2009. (Coleção Leitura e Formação). p. 17-39.

Enviado em: 11/08/2020

Revisado em: 10/03/2021

Aprovado em: 11/03/2021

Publicado em: 15/03/2021 